\title{
The Processing and Properties of Syntactic Al Foams Containing Low Cost Expanded Glass Particles
}

\author{
Andrew Wright, Andrew Kennedy* \\ Faculty of Engineering, University of Nottingham \\ University Park, Nottingham, NG7 2RD, UK \\ *Corresponding author: andrew.kennedy@nottingham.ac.uk
}

\begin{abstract}
Expanded glass particles (EGP) have been used to manufacture Al syntactic foams using a simple vacuum casting method. Clamping of the casting in the stainless steel mould was observed when preheating the mould to $>400^{\circ} \mathrm{C}$, causing damage to the EGP, resulting in a weaker foam but with the significant advantage of eliminating the yield drop, improving the energy absorption characteristics. The same effect in castings that were not clamped (for mould preheats $<400^{\circ} \mathrm{C}$ ) could be achieved by quenching in liquid nitrogen. These "low strength" syntactic metal foams are a costeffective alternative to metal foams and porous metals (in terms of specific strength, stiffness and energy absorption) rather than "conventional" syntactic foams which contain smaller, stronger, hollow microspheres.
\end{abstract}

\section{Introduction}

Al syntactic foams are materials synthesised by incorporating hollow particles, often hollow microspheres typically made from glass, silicon carbide or aluminosilicates, into an Al matrix. This results in a "composite" material with a lower density, higher specific strength and lower coefficient of thermal expansion than the base alloy. The foam properties depend on the properties of the hollow particles and the density of the foam, which can be affected by changing the volume fraction of sphere addition and the size and density of the hollow particles.

Applications for Al syntactic foams mainly focus on energy absorption, at higher stresses than those for porous metals and conventional metal foams, and thus their compressive deformation behaviour is of interest. ${ }^{[1-3]}$ Figure 1 presents a schematic stress - strain curve for an ideal energy absorber, ${ }^{[4]}$ with the key characteristic being the flat plateau which can extend to strains in excess of 50\%. Figure 1 also shows a typical stress - strain response for a syntactic Al foam where it is apparent that beyond the elastic limit there is a large load drop, ${ }^{[5]}$ which is more pronounced for smaller, stronger hollow spheres, and which it is believed to mark the onset of damage to the spheres and consequent reduction 
in their load bearing capacity. ${ }^{[5-7]}$ Although the crush strength may be 10 times that for an equivalent metal foam or porous metal, the rapid rise of stress with strain, which indicates the onset of densification, occurs at lower strains for syntactic foams, owing to their lower porosity. Syntactic foams of this type are far from ideal energy absorbers, with unwanted accelerations caused by the load drop and energy absorption efficiencies (the ratio of the energy absorbed to a given compressive strain to the theoretical maximum at that same strain) below $70 \%$.
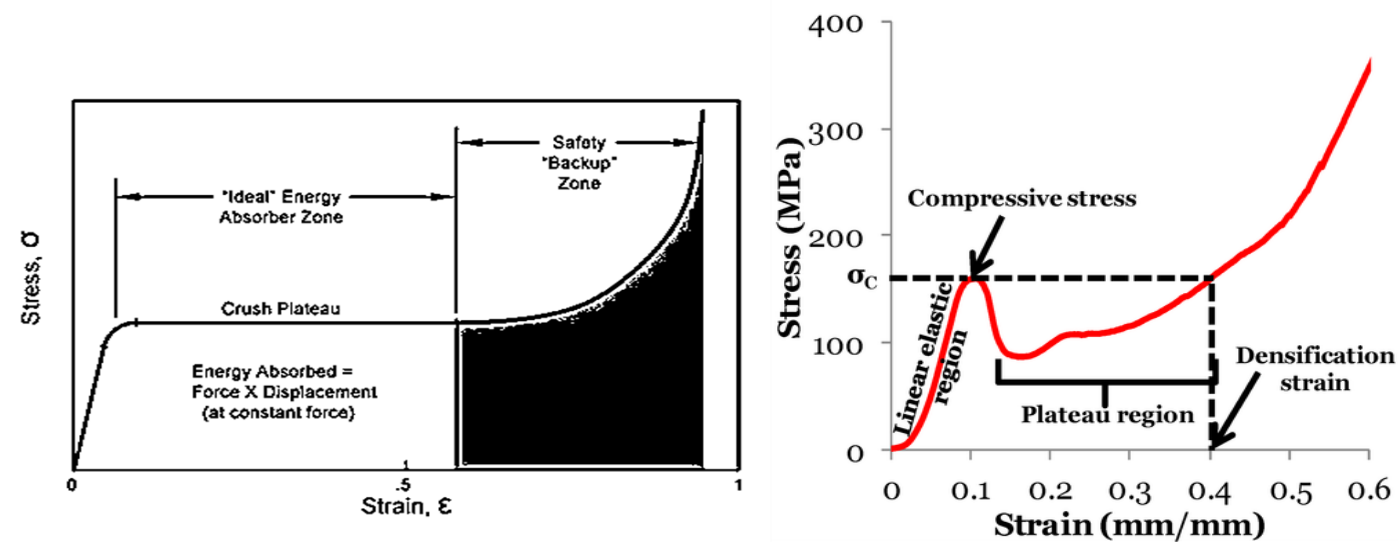

Figure 1 Stress - strain curves for (left) an ideal energy absorber and (right) a typical metal syntactic foam. ${ }^{[4,5]}$

Aluminium syntactic foams are commonly made by isothermal infiltration of a bed of hollow spheres with molten metal. Whilst this is a convenient and potentially low cost route, deleterious reactions between the hollow spheres and the molten metal matrix are possible and the requirement for a packed bed of hollow spheres means that there is limited ability to vary the sphere volume fraction outside the range for loose and dense random packing (roughly 0.6-0.65).

This leads to reasonably high densities for these materials $\left(1.5-1.9 \mathrm{~g} \mathrm{~cm}^{-3}\right)$ compared with conventional metal foams and porous metals $\left(0.6-1.0 \mathrm{~g} \mathrm{~cm}^{-3}\right)$. Whilst a wide range of spheres sizes have been used (from $\mu \mathrm{m}$ to mm), micron-sized hollow spheres are preferred, but their size necessitates high infiltration pressures increasing the likelihood of sphere cracking and penetration by the molten metal. Higher pressures also require larger and more costly processing apparatus, making the production of large, complex parts impractical. That said, syntactic foams offer the potential for low cost production (compared to metal foams or porous metals) of components with regular and reproducible pore structures and densities.

This study follows a different approach to the production of syntactic metal foams and rather than using micron-sized, strong, relatively dense ceramic hollow spheres, uses mm-sized highly porous, weak, expanded glass particles (EGP). These additions are expected to affect little strengthening, but provide a controlled level and distribution of porosity, 
retaining or even improving many of the processing, structural and cost benefits of syntactic foams, whilst enhancing the non-ideal crush behaviour.

\section{Methodology}

Expanded soda-lime glass particles (EGP) with a closed surface were used (supplied by OMYA). The approximate chemical composition (in wt.\%) of these particles is $69-73 \% \mathrm{SiO}_{2}, 11.5-13.5 \% \mathrm{Na}_{2} \mathrm{O}, 7.8-9.25 \% \mathrm{CaO}, 1-3 \% \mathrm{Al}_{2} \mathrm{O}_{3}, 1.99$ $2.5 \% \mathrm{MgO}, 0.99-1.2 \% \mathrm{~K}_{2} \mathrm{O}, 0.49-0.59 \% \mathrm{Fe}_{2} \mathrm{O}_{3}$. The roughly spherical beads are between 1 and $2 \mathrm{~mm}$ in diameter, with an average density of $0.35 \mathrm{~g} \mathrm{~cm}^{-3}$ (with an estimated porosity of $80-85 \%$ and a crush strength of $2-3 \mathrm{MPa}$ ). $15 \mathrm{~g}$ of beads were tap filled into a porous metal mould to a packing density of approximately $65 \%$, preheated in a muffle furnace at temperatures between $200-600^{\circ} \mathrm{C}$, and then infiltrated under a vacuum of approximately 0.9 bar with an Al- $12 \mathrm{wt} . \% \mathrm{Si}$ alloy heated to $780^{\circ} \mathrm{C}$. Cast foam "composite" samples were machined to $32 \mathrm{~mm}$ in diameter and $40 \mathrm{~mm}$ in length. A set of porous Al samples, made by replacing the EPG particles with salt spheres of the same size, were also produced, in this case preheating the mould at $600^{\circ} \mathrm{C}$. Samples were characterised using optical and scanning electron microscopy (SEM) along with X-ray micro-computed tomography (CT).

Quasi-static compression tests were performed at a constant rate of $0.4 \mathrm{~mm} \mathrm{~s}^{-1}$. Linear-variable displacement transducers were used to accurately measure displacement. Stiffness was measured by averaging over 4 loading and unloading cycles between 25 and $75 \%$ of the yield stress. A wide band acoustic emission (AE) transducer was connected (via coupling grease) to the base plate of the test rig, recording the energy of acoustic events during compression tests that exceeded a trigger value of $45 \mathrm{db}$, summing these events over $1.5 \mathrm{~s}$ time steps. The coefficient of thermal expansion (CTE) was measured using a TA instruments Q400 thermo-mechanical analyser, in most cases heating from room temperature to $200^{\circ} \mathrm{C}$ but also during cooling from room temperature to $-65^{\circ} \mathrm{C}$, in both cases at a ramp rate of $5^{\circ} \mathrm{C} \mathrm{min}^{-1}$. Samples were also examined using the same methods after having been immersed in liquid nitrogen until boiling of the liquid ceased, where after they were removed and then allowed to cool to room temperature.

\section{Results and Discussion}

Foam samples were successfully made under all the processing conditions investigated. Premature freezing was avoided even at the lowest preheating temperature, owing in part to the short infiltration times, but primarily because of the low thermal mass of the EGP bed. This was not the case for the salt particles used to make the porous Al 
sample, where the thermal mass, in $\mathrm{J} \mathrm{K}^{-1}$, is 5 times that for the EGP and the mould must be preheated at $600^{\circ} \mathrm{C}$ to avoid premature freezing. It was found that for mould preheats at or higher than $400^{\circ} \mathrm{C}$, the foam castings could not be removed from the mould by simply inverting the mould and tapping (this is not the case for infiltration of the salt particles where the casting is easily removed). Those castings that stuck were ejected by pressing them out. Figure 3 shows the compressive load required to force the samples from the mould, where it can be seen that higher mould temperatures exert greater clamping forces to the samples and that the maximum force for preheating at $600^{\circ} \mathrm{C}(40$ $\mathrm{kN})$ is 8 times higher than that for $500^{\circ} \mathrm{C}(5 \mathrm{kN})$. The diameter of the mould cavity, at room temperature, is $34.6 \mathrm{~mm}$, $\mathrm{NaCl}$-containing castings are typically $34.5 \mathrm{~mm}$ in diameter, as are EGP-containing samples cast with a $300^{\circ} \mathrm{C}$ mould preheat (since although the casting contracts less, the mould cavity is smaller at the casting temperature). EGPcontaining samples cast with a mould preheated at $600^{\circ} \mathrm{C}$, once they have been forcibly removed and have "sprungback", are $34.9 \mathrm{~mm}$ in diameter, confirming the significant compressive strain to which the samples were subjected.

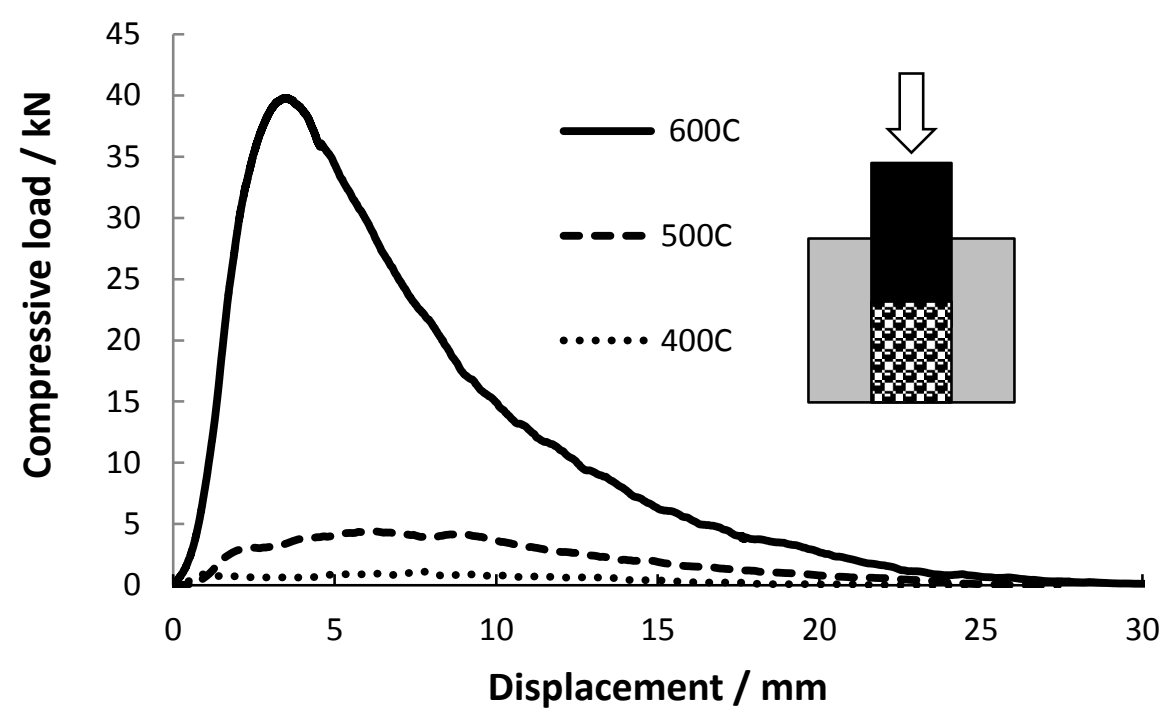

Figure 2 Force required to eject castings from the mould as a function of ram displacement

For preheating at $600^{\circ} \mathrm{C}$, the metal $\left(\mathrm{T}_{\mathrm{m}}=580^{\circ} \mathrm{C}\right)$ and mould cool together, for the other preheats the mould is colder than the metal as it freezes. The coefficient of thermal expansion (CTE) for a composite cast in a mould that was preheated at $200^{\circ} \mathrm{C}$ was measured (during cooling) to be $13.7 \times 10^{-6} \mathrm{~K}^{-1}$, showing that the EGP $\left(\mathrm{CTE}=8 \times 10^{-6} \mathrm{~K}^{-1}\right)$ restricts the contraction of the $\mathrm{Al}$ matrix $\left(\mathrm{CTE}=24 \times 10^{-6} \mathrm{~K}^{-1}\right)$ during cooling, decreasing the effective CTE for the "composite" to below that for the stainless steel mould $\left(\mathrm{CTE}=17 \times 10^{-6} \mathrm{~K}^{-1}\right)$. Thus, the mould will contract more for a given temperature drop and for the same temperature decrease, as is likely for the $600^{\circ} \mathrm{C}$ mould preheat, significant 
"clamping" of the casting by the mould will be experienced at room temperature, applying a significant compressive stress to the casting. Lower mould preheating temperatures result in smaller mould contractions making "clamping” less likely. Using the measured CTE value, a simple strain balance predicts release from the mould for preheating temperatures below approximately $460^{\circ} \mathrm{C}$, agreeing reasonably well with observations, since pouring the superheated metal into the mould increases its temperature by roughly $50^{\circ} \mathrm{C}$. No clamping was observed for the "composite" made with $\mathrm{NaCl}$ particles, even with a $600^{\circ} \mathrm{C}$ mould preheat, as the high $\mathrm{CTE}$ for the salt particles $\left(44 \times 10^{-6} \mathrm{~K}^{-1}\right)$ increases rather than decreases the contraction of the casting.

Figure 3 shows CT images of the EGP, showing they are well packed and distributed throughout the foams and illustrating their morphology and porous internal structure. This figure and Figure 4 show that the EGP typically contain pores with an average diameter between $100-200 \mu \mathrm{m}$, separated by thin walls a few $\mu \mathrm{m}$ thick. The matrix microstructure remained characteristic of a near-eutectic Al-Si alloy and energy dispersive X-ray analysis of the matrix did not reveal the presence of $\mathrm{Na}, \mathrm{Ca}$ or $\mathrm{Mg}$. "Clean" non-reacted interfaces are observed in Figure 4, aided by short (less than $3 \mathrm{~min}$ ) "exposure" times in the molten state. The EGP appear to have been intact during the infiltration stage, since no penetration by molten Al-Si during this process was observed, as evidence by CT images of the type shown in Figure 3. The density of the cast parts was found to be $1.14 \pm 0.1 \mathrm{~g} \mathrm{~cm}^{-3}$, with the scatter caused by variability in the packing fraction. From the EGP packing fraction and the density, the maximum foam density was estimated to be $1.17 \mathrm{~g} \mathrm{~cm}^{-3}$, indicating near complete (>97\%) filling of the porous EGP bed during infiltration, with only small un-infiltrated regions being apparent at the contact points between EGP particles (as seen in Figures 3 and 4).
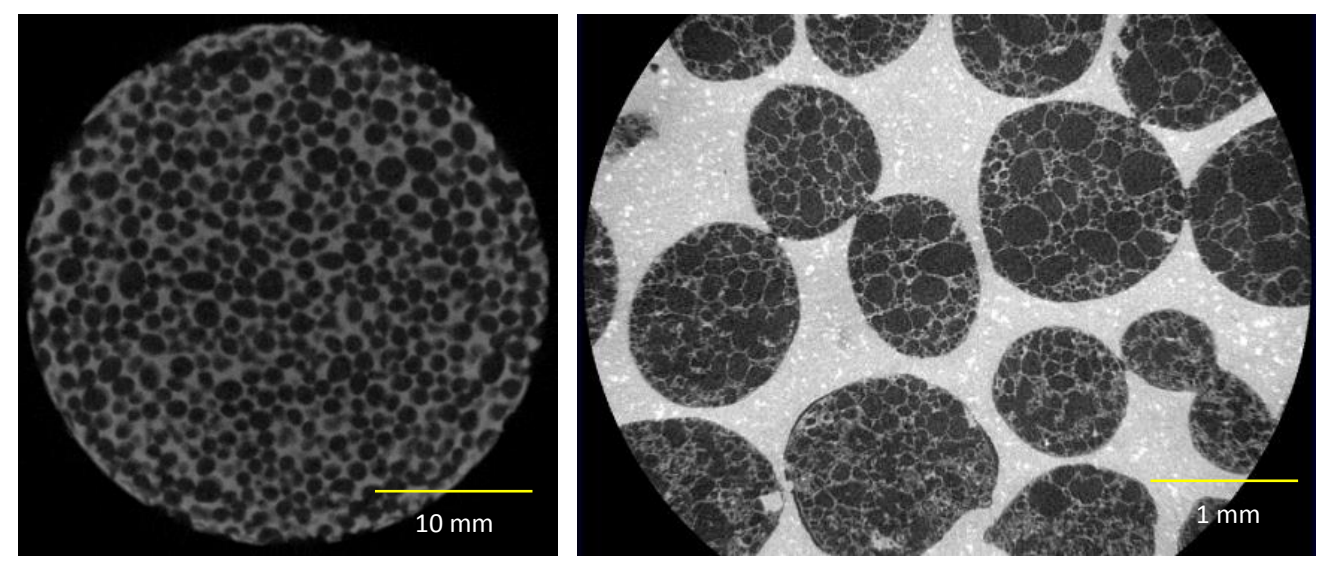

Figure $3 \mathrm{CT}$ images of the structure of Al-Si - EGP syntactic foams at (left) low and (right) high magnification 
Figure 5 shows stress-strain curves for foams made at different preheating temperatures and the property data are summarised in Table 1. The curves, with the exception of that for mould preheating at $600^{\circ} \mathrm{C}$, have similar forms, with small load drops after yielding and an increase in the rate of change of stress with strain at a strain of approximately 0.2 . The stiffness and crush strength at $25 \%$ strain decrease with increasing preheat temperature but despite the energy absorption also decreasing, the energy absorption efficiencies are similar (typically in the range of 84-88\%). Given that the load drops at yield are significantly smaller than those for "conventional" syntactic foams, as was shown in Figure 1, the energy absorption efficiencies are significantly higher and is similar to the behaviour reported in syntactic foams made with large weak perlite particles. ${ }^{[8]}$ Preheating the mould at $600^{\circ} \mathrm{C}$ results in a significant reduction in the crush strength, removal of the load drop and the flatter stress-strain curve increases the energy absorption efficiency.
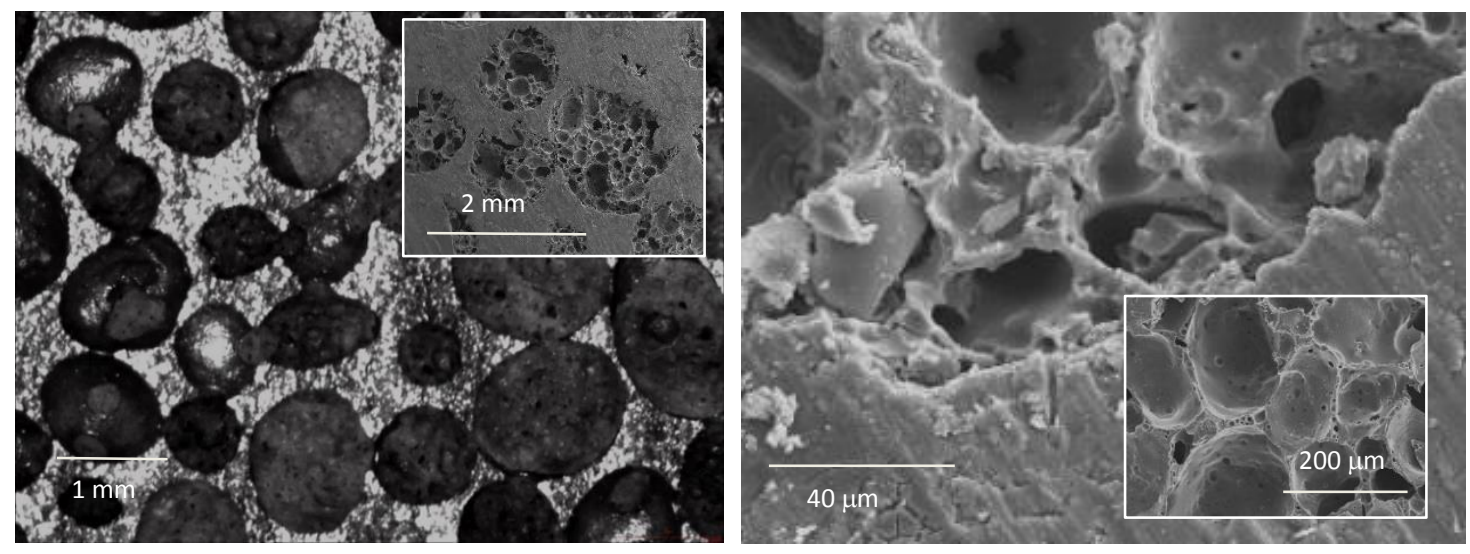

Figure 4 (Left) optical and (right) SEM micrographs of the structure of Al-Si - EGP syntactic foams

Table 1: Mechanical properties for the foams and porous Al

\begin{tabular}{|c|c|c|c|c|c|c|c|}
\hline Sample & $\begin{array}{l}\text { Mould } \\
\text { temperature } \\
/{ }^{\circ} \mathrm{C}\end{array}$ & Condition & $\begin{array}{l}\text { Density / } \\
\mathrm{g} \mathrm{cm}^{-3}\end{array}$ & $\mathrm{E} / \mathrm{MPa}$ & $\begin{array}{l}\mathrm{E}_{\mathrm{ab}} / \\
\mathrm{MJ} / \mathrm{m}^{-3}\end{array}$ & $\begin{array}{l}E_{a b} \\
\text { efficiency } \\
/ \%\end{array}$ & $\begin{array}{l}\text { Strength at } \\
25 \% \text { strain } \\
/ \mathrm{MPa}\end{array}$ \\
\hline EGP foam & 600 & As -cast & $1.15 \pm 0.01$ & $6.3 \pm 0.1$ & $5.3 \pm 0.1$ & 88 & 24.1 \\
\hline EGP foam & 600 & Quenched & $1.14 \pm 0.01$ & $6.3 \pm 0.1$ & $5.2 \pm 0.1$ & 88 & 23.7 \\
\hline EGP foam & 500 & As -cast & $1.14 \pm 0.01$ & $6.5 \pm 0.1$ & $6.1 \pm 0.1$ & 84 & 29.0 \\
\hline EGP foam & 400 & As -cast & $1.14 \pm 0.01$ & $6.6 \pm 0.1$ & $6.3 \pm 0.1$ & 84 & 30.1 \\
\hline EGP foam & 300 & As -cast & $1.14 \pm 0.01$ & $6.8 \pm 0.1$ & $6.8 \pm 0.1$ & 84 & 32.3 \\
\hline EGP foam & 300 & Quenched & $1.14 \pm 0.01$ & $5.9 \pm 0.1$ & $4.2 \pm 0.1$ & 88 & 19.0 \\
\hline EGP foam & 200 & As -cast & $1.13 \pm 0.01$ & $6.9 \pm 0.1$ & $7.0 \pm 0.1$ & 85 & 32.9 \\
\hline Porous Al & 600 & As -cast & $0.96 \pm 0.01$ & $5.3 \pm 0.1$ & $5.1 \pm 0.1$ & 92 & 22.3 \\
\hline
\end{tabular}

The mechanical response for an equivalent porous $\mathrm{Al}$ sample is also shown. This sample deforms at a low but fairly constant stress and has the highest energy absorption efficiency of all the samples tested. The introduction of the weak, brittle expanded glass particles does increase the stiffness (albeit slightly), the crush strength and energy absorbed, 
compared to a porous metal with the same metal fraction, by values in the range of $20-50 \%$, but these increases are small compared with those for additions of hollow ceramic spheres, where stiffer particles and stronger interfaces act as effective reinforcements to the $\mathrm{Al}$ matrix. ${ }^{[9]}$ The crushing of the porous glass particles and their densification within the collapsing porous metal structure results in a modest increase in stress with strain and slightly lower energy absorption efficiencies and reduced densifications strains compared with an equivalent porous metal. A significant reduction in the strength and energy absorption with high mould preheats and the disappearance of the load drop at yield for the highest preheat, supports the supposition that "clamping" of the mould induces damage to the EGP and what little mechanical enhancement they offered to the $\mathrm{Al}$ matrix is greatly reduced, such that their performance is similar to that for an equivalent porous metal.
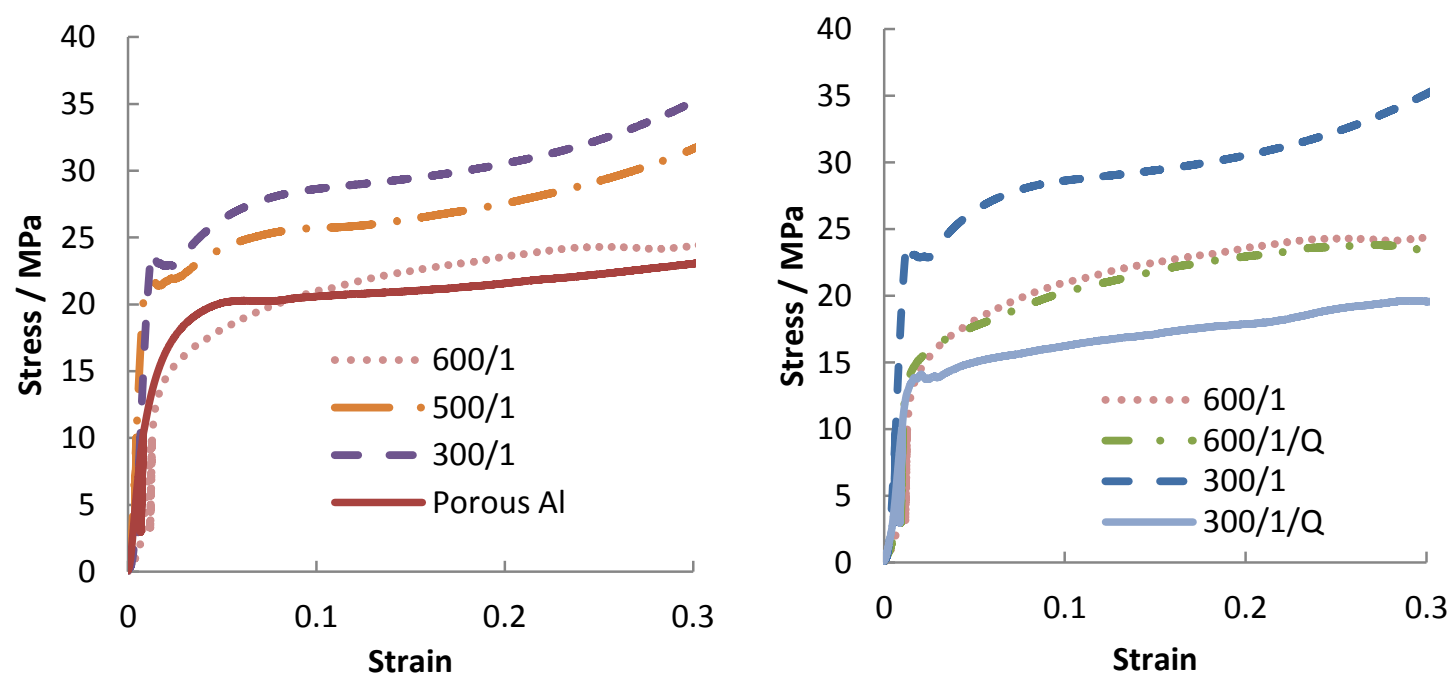

Figure 5 Stress - strain curves for (left) foams made with different mould preheats and (right) after quenching (Q) in liquid nitrogen

Figure 6 shows the typical trace for acoustic emission "events" as a function of time, plotted alongside the load data.

Few or no "events" above the threshold $45 \mathrm{~dB}$ limit were detected during cycling at low stresses in the elastic region (when the stiffness was being measured). A weak signal was recorded during the first cycle, for stresses above $6 \mathrm{MPa}$, but this was most likely due to local crushing of exposed EGP at the platen surfaces. For all samples, a strong maximum in the AE signal was detected at time points coincident with the onset of yielding, the magnitudes of which are presented in Table 2, along with the total energy. It should be noted that only a very weak signal (at least 3 orders of magnitude smaller) was detected when compressing a porous Al sample. The acoustic events support the hypothesis 
that EGP fracture predominantly occurs with the onset of plastic deformation of the foam. ${ }^{[10]}$ Weak signals beyond this point are likely to be a result of re-arrangement and further fragmentation of the EGP as their volume is reduced by continued compression. An important observation from both Table 1 and Figure 6 is that much smaller maxima and total energies are observed for castings made with higher mould preheats, consistent with higher levels of EGP damage in samples in which mould "clamping" is observed.

Table 2: Acoustic emission and CTE data for the foams and porous Al

\begin{tabular}{llllll}
\hline Sample & $\begin{array}{l}\text { Mould } \\
\text { temperature } \\
\text { / }{ }^{\circ} \mathrm{C}\end{array}$ & Condition & $\begin{array}{l}\text { CTE } / \\
\times 10^{-6} \mathrm{~K}^{-1}\end{array}$ & $\begin{array}{l}\text { AE max } \\
\times 10^{-9} \mathrm{aJ}\end{array}$ & $\begin{array}{l}\text { AE max } \\
\times 10^{-9} \mathrm{aJ}\end{array}$ \\
\hline EGP foam & 600 & As -cast & 21.5 & 0.6 & 8.8 \\
EGP foam & 600 & Quenched & 23.4 & 0.7 & 6.4 \\
EGP foam & 500 & As -cast & - & 1.3 & 7.0 \\
EGP foam & 400 & As -cast & - & 1.4 & 9.1 \\
EGP foam & 300 & As -cast & 18.9 & 9.1 & 58 \\
EGP foam & 300 & Quenched & 22.9 & 1.1 & 6.7 \\
EGP foam & 200 & As -cast & 17.4 & 16 & 77 \\
Porous Al & 600 & As -cast & 23.6 & 0.0006 & 0.017 \\
\hline
\end{tabular}
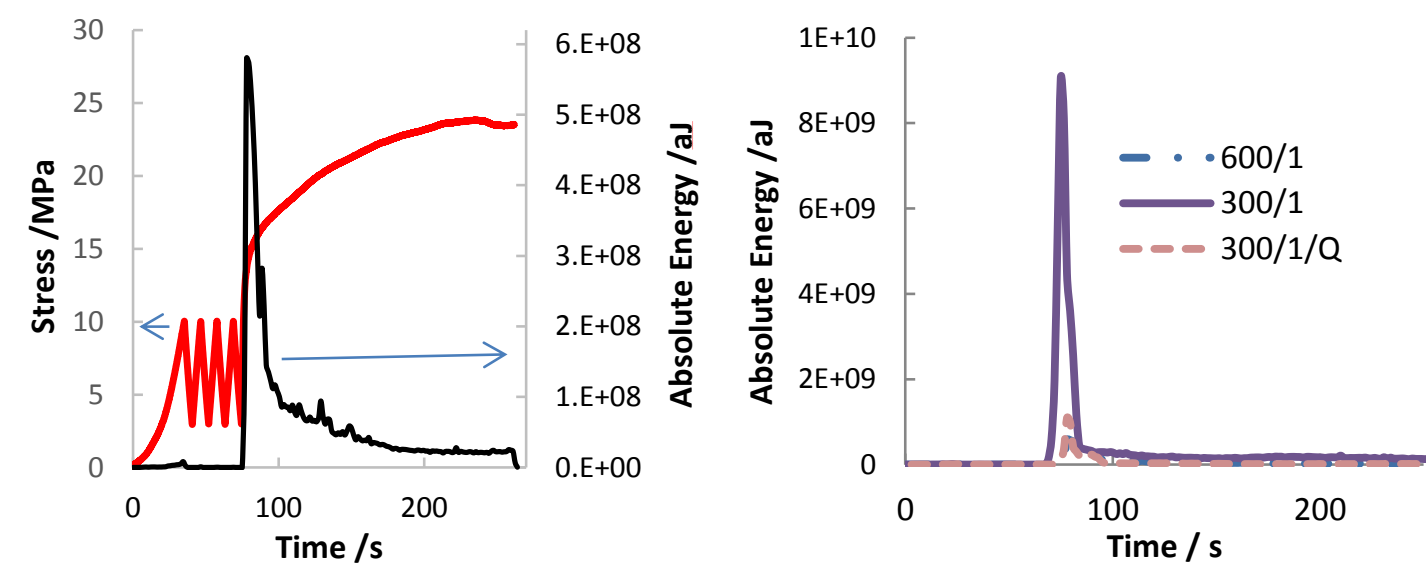

Figure 6 Acoustic emission (AE) traces (left) showing the relationship between AE signal and stress with time and (right) the effects of processing temperature and quenching

A modest reduction in the CTE is observed for samples made with mould preheats where mould release occurs $\left(200^{\circ} \mathrm{C}\right.$ and $300^{\circ} \mathrm{C}$ ) and little damage to the EGP is expected. This reduction is much smaller than that which is predicted by the rule of mixtures or the Turner model (or was observed during cooling, where the effect of the strength of the particle-matrix interface is expected to be less important). ${ }^{[1]}$ For preheating at $600^{\circ} \mathrm{C}$, no significant change in the CTE is measured, compared with the base alloy or the porous metal, consistent with the expectation that processing at this 
temperature results in widespread fracture of the beads. The interplay between the CTE differences within the "composite" casting and between the casting and the mould means that predicting the residual stress condition is not trivial. It is supposed that for higher mould preheats, damage to the EGP during cooling means that matrix contraction is unlikely to be constrained by the EGP and this is supported by stiffness, compressive strength and CTE values that vary very little from the equivalent porous Al sample. Those castings in which EGP are undamaged by mould "clamping" show characteristics of "reinforcement" (albeit slight) by the EGP additions, namely higher stiffness, a lower CTE and a higher compressive yield stress (which might in part be elevated by a tensile residual matrix stress).

Figure 5 and Table 1 show that quenching in liquid nitrogen has little effect on the mechanical response for samples preheated to $600^{\circ} \mathrm{C}$. For moulds heated to $300^{\circ} \mathrm{C}$, quenching greatly reduces the stiffness and energy absorbed, to values below those for preheating at $600^{\circ} \mathrm{C}$, the load drop at yield is no longer observed and the flatter form of the stress-strain curve results in an increase in the energy absorption efficiency. AE data in Figure 6 and Table 3 support the evidence for increased damage to the EGP as a result of quenching, as the fracture "events" for the quenched samples at low mould preheats are greatly reduced (unlike at high mould temperatures where the already damaged are unaffected). Similarly, quenching has limited effect on the CTE for syntactic foams made in moulds preheated to $600^{\circ} \mathrm{C}$, but the $\mathrm{CTE}$ of samples preheated to $300^{\circ} \mathrm{C}$ increases, commensurate with damage to the EGP caused by the quenching process. Cooling the samples by more than $200^{\circ} \mathrm{C}$ causes the EGP to be under increased compressive strain, causing extensive fracture. This process was evidenced by measuring AE "events" when quenching the end of a syntactic foam in liquid nitrogen (to protect the AE transducer from very low temperatures). Extensive high energy events were recorded for the sample made with a preheat at $300^{\circ} \mathrm{C}$; the sum of these events was 3 orders of magnitude smaller when preheating at $600^{\circ} \mathrm{C}$. After EGP fracture, and re-expansion during heating to room temperature, any residual stresses are likely to be relieved, resulting in a decrease in the compressive yield stress.

The performance indices for stiff or strong lightweight ties $(E / \rho, \sigma / \rho)$, beams or columns $\left(E^{1 / 2} / \rho, \sigma^{2 / 3} / \rho\right)$ or panels $\left(E^{1 / 3} / \rho, \sigma^{1 / 2} / \rho\right)$ can be calculated (using data in Table 1) and compared for the syntactic foam and equivalent porous metal made in this study. The two materials show a similar performance but the syntactic foams are marginally less attractive for lightweight panels owing to their high density. ${ }^{[1-5,12-15]}$ The energy absorbed is higher per unit volume or mass than for the equivalent porous metal, but much lower than for "conventional" syntactic foams. The much-reduced load drop in the foams presented in this study means that they show high energy absorption efficiencies (85-90\%) that are more typical of metal foams and porous metals than "conventional" syntactic foams.

The choice of large, highly porous EGP additions means that production of a syntactic foam with roughly $60 \%$ of uniformly-dispersed porosity is readily achieved (and this porosity can be increased if packing is enhanced by using 
multi-modal particle sizes). By the use of preforms of connected EGP, the method presented can be scaled up using processes such as low pressure die casting to manufacture large, complex foam parts. The low cost of the EGP (less than $10 \%$ of the price of $\mathrm{Al}$ per unit volume) means that these materials are cost-competitive with closed cell $\mathrm{Al}$ foams and porous $\mathrm{Al}$.

\section{Conclusion}

The use of large foamed glass (EGP) spheres makes the manufacture of Al syntactic foams with low densities (circa $1 \mathrm{~g}$ $\mathrm{cm}^{-3}$ ) simple, but to avoid clamping of the casting in the stainless steel mould, the mould should not be preheated above $400^{\circ} \mathrm{C}$. Mould clamping, aside from making component production impractical, causes damage to the EGP via stresses induced by CTE mismatch between the cooling foam and the mould. EGP fracture reduces the load bearing capacity of the spheres, causing the foam to become weaker as the EGP becomes more damaged, but has the significant advantage of eliminating the yield drop, improving the energy absorption characteristics.

A more practical way to introduce damage into "un-damaged" cast samples (that can be ejected from the casting moulds) is to quench the samples in liquid nitrogen. Quenched samples show the highest energy absorption efficiencies and a stress-strain response that is similar to porous Al with the same metal fraction. These "low strength" syntactic metal foams are a cost-effective alternative to metal foams and porous metals (in terms of specific strength, stiffness and energy absorption) rather than "conventional" syntactic foams made with smaller, stronger hollow microspheres.

\section{References}

[1] P.K. Rohatgi, J.K. Kim, N. Gupta, S. Alaraj, A. Daoud, Composites Part A: 2006, A37, 430.

[2] M. Kiser, M.Y. He, F.W. Zok, Acta Mater. 1999, 47, 2685.

[3] L.P. Zhang, Y.Y. Zhao, J. Compos. Mater., 2007 41, 2105

[4] M. Altenaiji, G.K. Schleyer, Y.Y. Zhao, in Composites and Their Properties (Ed. Ning Hu), InTech, 2012 pp. 437-454.

[5] J. Cox, D. D. Luong, V. C. Shunmugasamy, N. Gupta, O. M. Strbik III and K. Cho, Metals, 2014, 4, 530.

[6] D.K. Balch, J.G.O. Dwyer, G.R. Davis, C.M. Cady, G.T. Gray III, D.C. Dunand, Mater. Sci. Eng. A, 2005, A391, 408.

[7] G.H. Wu, Z.Y. Dou, D.L. Sun, L.T. Jiang, B.S. Ding, B.F. He, Scripta Mater., 2007, 56, 221. 
[8] M. Taherishargh, I.V. Belova, G.E. Murch, T. Fiedler, Mater. Sci. Eng. A, 2014, A604, 127.

[9] D.K. Balch, and D.C. Dunand, Acta Mater., 2006, 54, 1501.

[10] C. Kádár, K. Máthis, I. N. Orbulov, F. Chmelí, Materials Letters, 2016, 173, 31.

[11] P. K. Rohatgi, N. Gupta, S Alaraj, J. Comp Mater., 2006, 40, 1163.

[12] M.F. Ashby, A. Evans, N.A. Fleck, J.W. Hutchinson, H N G Wadley, L J Gibson, Metal Foams: A Design Guide, Butterworth-Heinemann, Burlington 2000

[13] D. Ruan, G. Lu, F. Chen, E Siores, Composite Structures, 2002, 57, 331.

[14] N Gupta, E. Woldesenbet, P Mensah, Composites Part A:, 2004, 35, 103.

[15] L. Licitra, D. D. Luong, O.M. Strbik III, N. Gupta, Materials \& Design, 2014, 66, 504. 


\section{Figure Captions}

Figure 1 Stress - strain curves for (left) an ideal energy absorber and (right) a typical metal syntactic foam. ${ }^{[4,5]}$

Figure 2 Force required to eject castings from the mould as a function of ram displacement

Figure $3 \mathrm{CT}$ images of the structure of Al-Si - EGP syntactic foams at (left) low and (right) high magnification

Figure 4 (Left) optical and (right) SEM micrographs of the structure of Al-Si - EGP syntactic foams

Figure 5 Stress - strain curves for (left) foams made with different mould preheats and (right) after quenching (Q) in liquid nitrogen

Figure 6 Acoustic emission (AE) traces (left) showing the relationship between AE signal and stress with time and (right) the effects of processing temperature and quenching 


\section{Table of Contents (50-60 words)}

Foamed glass spheres can be used to make Al syntactic foams with low densities via a simple casting method. Paradoxically, enhanced energy absorption was achieved when the spheres were extensively damaged during processing or via an additional quenching step. These "low strength" foams are a cost-effective alternative to metal foams and porous metals rather than "traditional" syntactic foams.

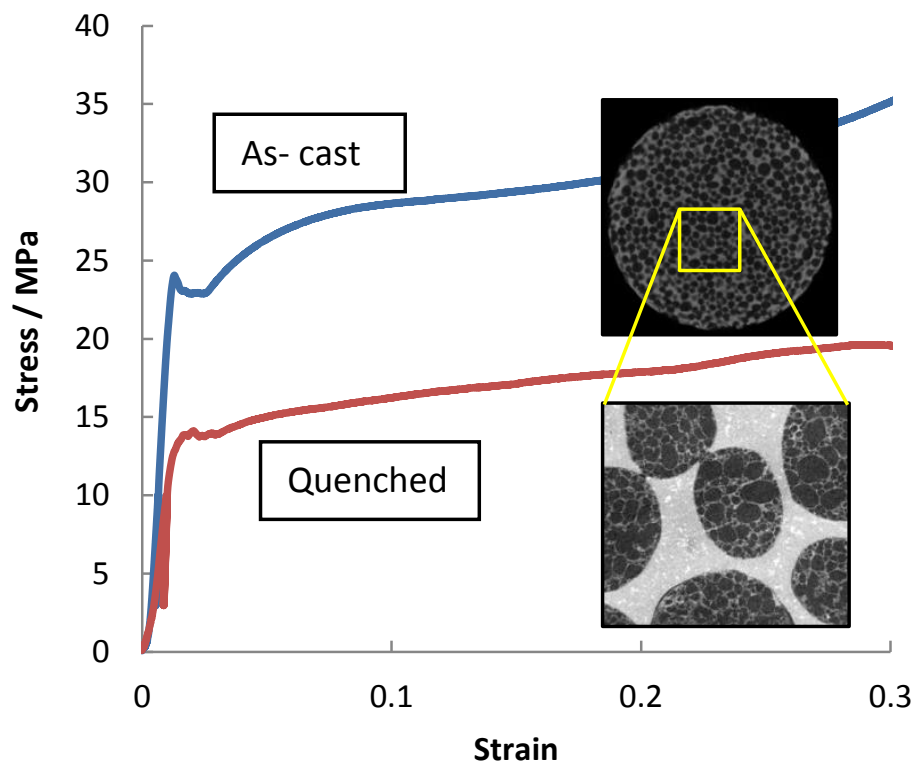

